\title{
Evaluating the German oncology certification system and its implications for colorectal carcinoma - a national and international comparison of relative survival rates.
}

\author{
Maximilian Richter ${ }^{1}$, Lena Sonnow ${ }^{2}$, Amir Mehdizadeh-Shrifi ${ }^{2}$, Axel Richter ${ }^{3}$, Rainer \\ Koch $^{4}$, and Alexander Zipprich ${ }^{1}$ \\ ${ }^{1}$ Martin-Luther-Universität Halle-Wittenberg \\ ${ }^{2}$ Medizinische Hochschule Hannover \\ ${ }^{3}$ HELIOS Klinikum Hildesheim \\ ${ }^{4}$ Technische Universität Dresden
}

May 20, 2020

\begin{abstract}
Rationale, aims and objectives In order to evaluate how the certification of specialised Oncology Centres in Germany affects the relative survival of patients with colorectal cancer (CRC), a national and international comparison was performed. Method Between 2007 and 2013, 675 patients with colorectal cancer treated at the Hildesheim Hospital, an academic teaching hospital of the Hanover Medical School (MHH), were included. A follow up of the entire patient group was performed until 2014 . To obtain international data, a SEER-database search was done. The relative survival of 148,957 patients was compared to our data after 12, 36 and 60 months. For national survival data, we compared our rates with 36,048 patients of the Munich Cancer Registry (MCR) Results Relative survival at Certified Oncology Centres was significantly higher in advanced tumour stages compared with national and international cancer registry data. Nationally, we found only little variation in survival rates for low stage (UICC I, II) CRC, colon, and rectal carcinoma. Both colon and rectal carcinoma showed notable variations in their relative survival rates for advanced tumour stages. These variations were even more distinct for rectal carcinoma (Hildesheim Hospital: 89.9\%, 40.3\%, 30.1\%; Munich Cancer Registry (MCR): 63.6\%, 26.2\%, 15.2\%). The international comparison for colorectal cancer, colon cancer and rectal cancer showed significantly higher survival rates for patients with advanced tumour stages at the Certified Cancer Centre. CRC (UICC IV) at month 12 had a relative survival of $77 \%$ whereas the international survival was only $54,9 \%$ (raw $\mathrm{p}<0.001$ ). Conclusion Our findings suggest that patients with advanced tumour stages of CRC and rectal cancer, benefit most from multidisciplinary treatment at Certified Oncology Centres as compared to low stage CRC and rectal carcinoma. However, the creation of unified national registry data bases is necessary for future evaluation of cancer treatment and improved international comparison.
\end{abstract}

\section{Hosted file}

Main Document.doc available at https://authorea.com/users/324641/articles/452763-evaluatingthe-german-oncology-certification-system-and-its-implications-for-colorectal-carcinomaa-national-and-international-comparison-of-relative-survival-rates 


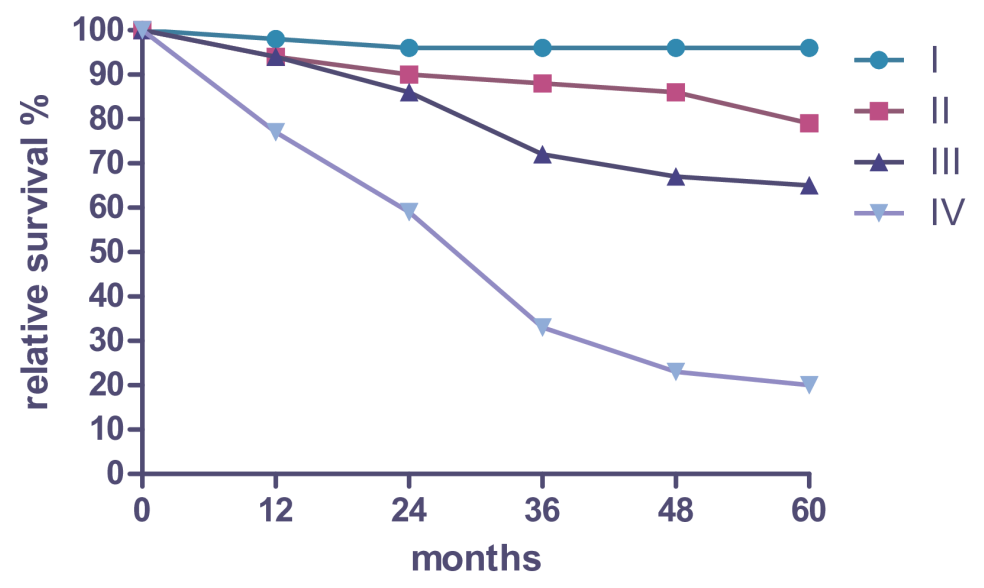

\begin{tabular}{|c|c|c|c|c|c|c|}
\hline \multicolumn{6}{|l|}{ Patients at risk } \\
\hline Months & 0 & 12 & 24 & 36 & 48 & 60 \\
\hline I & 144 & 112 & 72 & 49 & 37 & 17 \\
\hline II & 195 & 148 & 99 & 69 & 43 & 15 \\
\hline III & 180 & 139 & 89 & 52 & 32 & 14 \\
\hline IV & 106 & 66 & 37 & 14 & 5 & 0 \\
\hline
\end{tabular}

Figure 01. Relative survival by stage for CRC and patients at risk from 2007-2013 in Hildesheim 


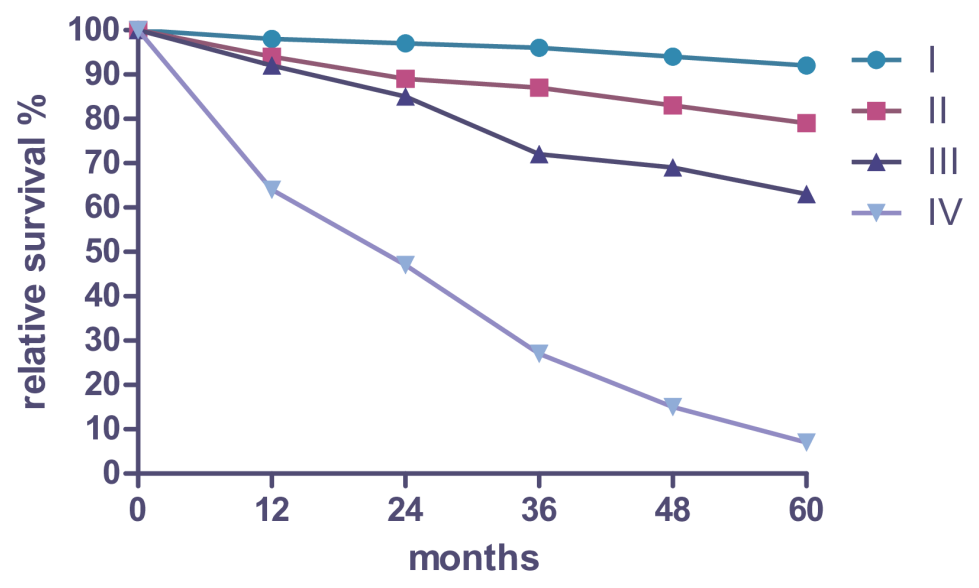

\begin{tabular}{|c|c|c|c|c|c|c|}
\hline \multicolumn{6}{|l|}{ Patients at risk } \\
\hline Months & 0 & 12 & 24 & 36 & 48 & 60 \\
\hline I & 84 & 63 & 38 & 25 & 21 & 8 \\
\hline II & 138 & 105 & 75 & 54 & 34 & 12 \\
\hline III & 113 & 84 & 55 & 34 & 20 & 9 \\
\hline IV & 55 & 29 & 17 & 8 & 2 & 0 \\
\hline
\end{tabular}

Figure 02. Relative survival by stage for colon cancer and patients at risk from 2007-2013 in Hildesheim 


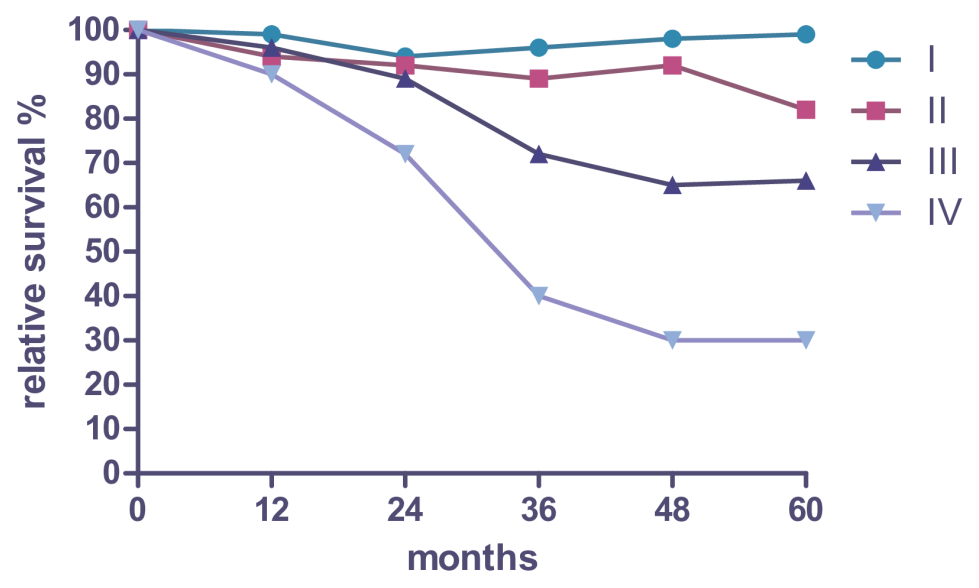

\begin{tabular}{|l|c|c|c|c|c|c|}
\hline Patients at risk & 0 & 12 & 24 & 36 & 48 & 60 \\
\hline Months & 59 & 49 & 37 & 27 & 18 & 10 \\
\hline I & 57 & 46 & 31 & 23 & 16 & 5 \\
\hline II & 67 & 58 & 45 & 27 & 18 & 10 \\
\hline III & 51 & 40 & 27 & 13 & 6 & 0 \\
\hline IV &
\end{tabular}

Figure 03. Relative survival by stage for rectal cancer and patients at risk from 2007-2013 in Hildesheim 